\section{RSP}

http://www.rsp.fsp.usp.br/
Revista de Saúde Pública

\title{
Alcohol-related disorders and associated factors in a rural area in Brazil
}

\author{
Gustavo Pêgas Jaeger', Christian Loret de Mola", Mariangela Freitas Silveira'II \\ ' Universidade Federal de Pelotas. Faculdade de Medicina. Programa de Pós-Graduação em Epidemiologia. \\ Pelotas, RS, Brasil \\ " Universidade Federal de Pelotas. Faculdade de Enfermagem. Departamento de Enfermagem. Pelotas, RS, Brasil \\ III Universidade Federal de Pelotas. Faculdade de Medicina. Departamento Materno Infantil e de Pós-Graduação \\ em Epidemiologia. Pelotas, RS, Brasil
}

\section{ABSTRACT}

OBJECTIVE: To describe the prevalence of alcohol-related disorders and associated factors in an exclusively rural population.

METHODS: This is a cross-sectional, population-based study of a rural research consortium, conducted in a medium-sized city in Southern Brazil, with adults living in a rural area, using the AUDIT (Alcohol Use Disorders Identification Test). The analysis included the prevalence of alcohol-related disorders and associated factors, such as the sociodemographic, family, and health factors; it was carried out by Poisson regression, in a hierarchical analysis model, with a 95\% confidence interval.

RESULTS: The final sample amounted to 1,519 subjects. The prevalence of alcohol-related disorders (AUDIT $\geq 8$ ) was 8.4\% (95\%CI 7.0-9.8). Risk factors for alcohol-related disorders were being male ( $\mathrm{PR}=8.2,95 \% \mathrm{CI} 4.82-14.16)$, age group between 18 and 29 years $(\mathrm{PR}=3.29,95 \% \mathrm{CI}$ $1.80-6.0$ ), and smoking ( $\mathrm{PR}=1.88,95 \% \mathrm{CI} 1.03-3.43)$. The practice of religion $(\mathrm{PR}=0.38,95 \% \mathrm{CI}$ $0.25-0.58)$ and education level between nine and 11 years $(\mathrm{PR}=0.33$, 95\%CI 0.16-0.69) were protective factors with statistical significance. Marital status and social status were not associated with the outcome studied.

Correspondence:

Gustavo Pêgas Jaeger Programa de Pós-Graduação em Epidemiologia - UFPel Rua Marechal Deodoro, 1160 $3^{\circ}$ piso Centro

96020-220 Pelotas, RS, Brasil E-mail: gpjaeger@yahoo.com.br

Received: May 31, 2017

Approved: Nov 2, 2017

How to cite: Jaeger GP, Loret de Mola C, Silveira MF. Alcohol-related disorders and associated factors in a rural area in Brazil. Rev Saude Publica. 2018;52 Suppl 1:8s.

Copyright: This is an open-access article distributed under the terms of the Creative Commons Attribution License, which permits unrestricted use, distribution, and reproduction in any medium, provided that the original author and source are credited.

CONCLUSIONS: The prevalence of alcohol-related disorders in the rural population is high, but, on average, it is lower than that found in urban populations. Risk and protective factors were similar to those found in previous studies. Men, younger persons, and smokers are at higher risk for alcohol-related disorders. On the other hand, practicing a religion and having a higher education level were protective factors.

DESCRIPTORS: Alcohol Drinking, epidemiology. Alcohol-Induced Disorders, epidemiology. Alcoholism, epidemiology. Risk Factors. Socioeconomic Factors. Rural Population. 


\section{INTRODUCTION}

The pattern of alcohol consumption of the adult Brazilian population has been the object of several research studies in the last decades ${ }^{1-3}$. These studies are important because this pattern is related to several health problems, as well as social and economic issues ${ }^{2,4}$.

Current scientific literature uses different nomenclatures to refer to different patterns of alcohol consumption ${ }^{5}$. The World Health Organization (WHO) defines three for them. The at-risk use is described as a pattern that increases the possibility of harm to the consumer or others. Harmful use is defined as a pattern that results in physical or mental harm. Dependence is characterized by a set of physiological, behavioral, and cognitive signs and symptoms, such as a strong desire to consume alcohol and difficulty to stop consumption, which denote a more serious pattern 5 .

In a report published by the WHO in 2014, alcohol is described as a substance capable of leading to chemical dependence and causing serious health problems, such as liver cirrhosis, various cancers, and pancreatitis ${ }^{4}$. The number of deaths attributed to alcohol consumption in 2012 was 3.3 million, representing 5.9\% of all deaths in the world that year ${ }^{4}$. Harmful alcohol consumption leads to economic losses to nations. South Korea and Thailand, middle-income countries as Brazil, had a total cost with alcohol abuse of approximately $2.1 \%$ of their gross domestic product ${ }^{6}$. In Brazil, large national studies have researched alcohol consumption. The II National Survey of Alcohol and Drugs (LENAD-II) carried out in 2012 found an overall prevalence of alcohol dependence of $6.8 \%^{2}$. Another large survey, the National Health Survey (PNS) of 2013, found a prevalence of $10.3 \%$ of alcohol abuse, defined as the consumption of five or more doses for men and four or more doses for women on a single occasion in the last 30 days $^{3}$. In addition to these national surveys, smaller studies have been carried out to know in detail the pattern, prevalence, and factors associated with alcohol consumption in Brazil. A study conducted in $2012^{7}$ with the urban population of the city of Florianópolis, State of Santa Catarina, Brazil, using the Alcohol Use Disorders Identification Test (AUDIT) questionnaire ${ }^{5}$, found a prevalence of $18.4 \%$ of alcohol-related disorders. In Pelotas, State of Rio Grande do Sul, Brazil, in 2004, a study also conducted with the urban population found a prevalence of $14.3 \%$ of alcohol abuse (30 grams or more per day) $)^{8}$.

Some factors associated with higher alcohol consumption are known and more consistent in current literature, such as being male, being single or divorced, and being a smoker. However, the relationship with some important sociodemographic factors, such as age group, social class, education level, income, among others, is not well established ${ }^{1,7-9}$.

Although knowledge about the pattern of alcohol consumption in the Brazilian population has grown considerably, few data can be found in the literature on it in rural populations ${ }^{2,3,10}$. In one of these studies with quilombola communities, in 2015, a prevalence of $10.7 \%$ was found for excessive alcohol consumption and an association with higher education level, smoking, and work exercise. Excessive consumption in this study was classified as five or more doses for men and four or more doses for women on a single occasion or regular consumption of 15 or more doses per week ${ }^{10}$.

Unlike Brazil, we can find studies in the literature in other countries on alcohol consumption and alcohol-related problems in exclusively rural regions. A study conducted in rural India in 2013 found a prevalence of $9.4 \%$ of alcohol consumption and 3.7\% of at-risk alcohol consumption. In this study, alcohol consumption was associated with males, intermediary age group (15-44 years), low education level, and smoking ${ }^{11}$. Another study carried out with the rural population of Vietnam in the same year found a prevalence of alcohol-related problems of $11.8 \%$, with a strong association with males ${ }^{12}$.

In this study, we describe the prevalence of alcohol-related disorders and their associated factors in the rural population of a medium-sized city in Southern Brazil. 


\section{METHODS}

This population-based, cross-sectional study was conducted in the rural area of the city of Pelotas, State of Rio Grande do Sul, Brazil, with individuals aged 18 years or over. It is part of the research consortium of the 2015/2016 biennium of the Graduate Program in Epidemiology of the Universidade Federal de Pelotas ${ }^{13}$. Pelotas is located in the Southern region of the state of Rio Grande do Sul. The total population of the municipality in 2010 was 328,275 inhabitants, of which approximately 17,000 were aged 18 years or over and lived in the rural area. The rural area of Pelotas consists of eight districts, divided in 50 census tracts according to criteria of the Brazilian Institute of Geography and Statistics (IBGE) ${ }^{14}$.

The sample consisted of individuals from all districts of the rural area of the city of Pelotas. The sample size of the consortium was defined based on the needs of nine subprojects. For this study, the minimum sample size was 1,440 individuals, calculated in the OpenEpi program $^{15}$. The parameters used to calculate the sample size were $15 \%$ prevalence of the main outcome (alcohol-related disorders), estimated by the mean prevalence of two studies with similar design and another one performed in the urban area of Pelotas ${ }^{7,8,16}$, acceptable error of three percentage points (pp), design effect of two, $95 \%$ confidence interval, statistical power of $80 \%$, minimum odds ratio of 1.8 , in addition to $10 \%$ for losses and refusals and $15 \%$ for confounding factors.

The sampling process was carried out in multiple stages. Initially, 24 of the 50 census tracts that make up the rural area were drawn. Then, 30 households from each tract were randomly selected to reach the minimum sample value, estimating that each household would have at least two adults. We used the Google Earth software to identify households in each tract.

Field work was carried out between January and June 2016. A group of interviewers was trained to apply the research instruments, using electronic questionnaires on tablets, using RedCap (Research Electronic Data Capture) software, and traditional paper questionnaires. They also received training and were standardized in the collection of anthropometric data. The field work always had the supervision of at least two Master's students responsible for the consortium.

In the field of research, it was fundamental to use a GPS device (Global Positioning System). From a previously defined process for sample selection, the path started using the geographical coordinates provided by the GPS for the location of the residences. Further details on the methodology of the field work are available in the methodological article of this research consortium ${ }^{16}$.

To evaluate alcohol consumption, we used the AUDIT, which is a screening instrument developed by the WHO, already validated in Brazil ${ }^{7,17}$, with 10 questions that can generate a total score from zero to 40 points. In this study, we used the AUDIT version validated in the city of Pelotas ${ }^{17}$. The WHO proposes a subdivision, according to the scores obtained in the AUDIT, into four categories or patterns of alcohol consumption: zero to seven, low-risk use; eight to 15, at-risk use; 16 to 19, harmful use; and 20 or more, likely dependent. In addition, the AUDIT is also used in a dichotomized manner, from zero to seven points in the category considered "low-risk use", and $\geq 8$ points in the category called "alcohol-related disorders", used as the outcome of this study, which includes the subcategories at-risk use, harmful use, and likely dependent?

The exposure variables studied were categorized as: sex (male; female), age group (18-29; 30-39; 40-49;50-59; $\geq 60$ years), self-reported race (white; black; brown, yellow, or indigenous), self-reported family ancestry (German or Pomeranian; Brazilian or mixed; Italian; Portuguese; African or Quilombola; Polish; other), family history of alcohol-related problems (no; yes), education level in full years (zero; $1-4 ; 5-8 ; 9-11 ; \geq 12$ ), marital status (married or with partner; divorced, separated, or widowed; single), current work (no; yes), socioeconomic class (A-B; $\mathrm{C}$; D-E), using the Brazilian Association of Research Companies (ABEP ${ }^{18}$, religion (no; yes), 
religious choice (Catholic; Evangelical; Afro-Brazilian; Spiritist; other), religious practice in the last 30 days (none; $\geq$ once), using the question "From < day > of last month, how often did you go to Mass, worship, or religious session?", smoking (current smoker; former smoker; never smoked), likely current diagnosis of depression (no; yes), using the Edinburgh depression scale with cutoff point $\geq 13$ for likely diagnosis ${ }^{19}$, alcohol use at some point in life (no; yes), age of first experience with alcohol ( $<18$; $\geq 18$ years).

In order to perform the bivariate and multivariate association analyses, we chose to use the dichotomized version of the outcome variable to increase the statistical power. In these analyses, we used the Wald test for heterogeneity and trend test to calculate $\mathrm{p}$ values. We performed multivariate analyses using a hierarchical conceptual and theoretical model ${ }^{20}$ at four levels, from the most distant to the most proximal to the outcome.

At the first level of the model, we include the variables of sex, age, family ancestry, and family history of alcoholism. In the second level, we included marital status, education level, current work, socioeconomic classification, and type of religion. The third level consisted of only the variable of religious practice. In the fourth and last hierarchical level, we included the variables of smoking, likely diagnosis of depression, and age of first experience with alcohol.

The hierarchical model was used as the basis for the statistical analyses. The variables of each hierarchical level were adjusted to each other. From the second level, the adjustments were also made by the variable clusters of the previous levels. This approach presents some advantages, such as keeping the adjustment for potentially confounding variables and avoiding adjustment for possibly mediating variables of the studied process ${ }^{20}$.

The analyses were performed by Poisson regression for the calculation of prevalence ratios (PR), and we kept the variables with $p<0.20$ in the bivariate analysis in the model. Throughout the statistical analysis process, we used the svy command because the sampling process was carried out in multiple stages, with drawing of clusters and not individuals, in addition to considering the different sample sizes in each district. We performed the analyses using the Stata 14.1 statistical package.

Quality control was carried out by applying 10 questions from the original questionnaire to $10 \%$ of the total sample by telephone. Concordance was calculated by the Kappa test.

The study was approved by the Research Ethics Committee of the Faculdade de Medicina of the Universidade Federal de Pelotas (Process 1.363.979, December 11, 2015). All research participants signed an informed consent.

\section{RESULTS}

The sample consisted of 1,697 individuals living in the rural area. Of these, 1,519 completed the research, which resulted in $10.5 \%$ of losses and refusals. The weighted Kappa coefficient was 0.90 for the smoking question and 0.51 for the question on the age of the first experience with alcohol. Of the sample, $51.7 \%$ were female, $85.2 \%$ self-reported as whites, and $41.0 \%$ self-reported as descended from Germans or Pomeranians. Most had five to eight years of study (42.6\%), worked at the time of the research (59.0\%), and belonged to socioeconomic class C (53.7\%). Regarding marital status, $60.3 \%$ reported being married or living with a partner, and $4.4 \%$ reported being divorced or separated. Most (86\%) reported having some kind of religion. Of these, $46.5 \%$ self-reported as Catholics and $45.0 \%$ as Evangelicals. In addition, $50.6 \%$ reported practicing their religion at least once a month (Table 1 ).

We found alcohol-related disorders, an AUDIT score category $\geq 8$ points, in $8.4 \%$ of the 1,519 adults studied, with a significant difference between sexes, being it $15.5 \%$ in men and $1.9 \%$ in women. Among the patterns of alcohol consumption, likely dependence presented a prevalence of $0.7 \%$ (Figures 1 and 2 ). 
Table 1. Description of the sample of individuals aged 18 years or over living in the rural area of the city of Pelotas, State of Rio Grande do Sul, Brazil, 2016. $(n=1,519)$

\begin{tabular}{|c|c|c|}
\hline Characteristic & $\mathbf{n}^{\mathrm{a}}$ & $\%$ \\
\hline \multicolumn{3}{|l|}{ Sex } \\
\hline Male & 734 & 48.3 \\
\hline Female & 785 & 51.7 \\
\hline \multicolumn{3}{|l|}{ Age group (years) } \\
\hline $18-29$ & 287 & 18.9 \\
\hline $30-39$ & 228 & 15.0 \\
\hline $40-49$ & 296 & 19.5 \\
\hline $50-59$ & 297 & 19.5 \\
\hline 60 or over & 411 & 27.1 \\
\hline \multicolumn{3}{|l|}{ Race } \\
\hline White & 1,296 & 85.0 \\
\hline Black & 92 & 6.0 \\
\hline Brown & 101 & 6.9 \\
\hline Yellow & 21 & 1.4 \\
\hline Indigenous & 9 & 0.7 \\
\hline \multicolumn{3}{|l|}{ Family ancestry } \\
\hline German/Pomeranian & 632 & 41.0 \\
\hline Brazilian/Mixed & 386 & 26.0 \\
\hline Italian & 171 & 11.4 \\
\hline Portuguese & 88 & 5.8 \\
\hline African/Quilombo & 75 & 5.0 \\
\hline Other & 167 & 10.8 \\
\hline \multicolumn{3}{|c|}{ Family history of problems with alcohol } \\
\hline No & 1,074 & 70.9 \\
\hline Yes & 441 & 29.1 \\
\hline \multicolumn{3}{|l|}{ Education level } \\
\hline 0 & 39 & 2.6 \\
\hline $1-4$ & 435 & 28.7 \\
\hline $5-8$ & 648 & 42.6 \\
\hline $9-11$ & 360 & 23.6 \\
\hline 12 or over & 37 & 2.5 \\
\hline \multicolumn{3}{|l|}{ Marital status } \\
\hline Married/Partner & 920 & 60.3 \\
\hline Divorced/Separated & 67 & 4.4 \\
\hline Single & 397 & 26.4 \\
\hline Widow & 135 & 8.9 \\
\hline \multicolumn{3}{|l|}{ Current work } \\
\hline No & 613 & 41.0 \\
\hline Yes & 906 & 59.0 \\
\hline \multicolumn{3}{|c|}{ Socioeconomic class (ABEP) } \\
\hline$A$ or $B$ & 301 & 20.0 \\
\hline C & 814 & 53.7 \\
\hline $\mathrm{D}$ or $\mathrm{E}$ & 388 & 26.3 \\
\hline \multicolumn{3}{|l|}{ Religion } \\
\hline No & 212 & 14.0 \\
\hline Yes & 1,307 & 86.0 \\
\hline \multicolumn{3}{|l|}{ Religious choice } \\
\hline Evangelical & 595 & 45.0 \\
\hline Catholic & 599 & 46.5 \\
\hline Spiritist & 38 & 2.9 \\
\hline Afro-Brazilian & 11 & 0.9 \\
\hline
\end{tabular}

Continue 
Table 1. Description of the sample of individuals aged 18 years or over living in the rural area of the city of Pelotas, State of Rio Grande do Sul, Brazil, 2016. $(n=1,519)$ Continuation

\begin{tabular}{|c|c|c|}
\hline Other & 61 & 4.7 \\
\hline \multicolumn{3}{|l|}{ Religious practice } \\
\hline Zero/month & 660 & 49.4 \\
\hline$\geq 1 /$ month & 645 & 50.6 \\
\hline \multicolumn{3}{|l|}{ Smoking } \\
\hline Never smoked & 987 & 64.7 \\
\hline Former smoker & 285 & 18.7 \\
\hline Current smoker & 247 & 16.6 \\
\hline \multicolumn{3}{|c|}{ Diagnosis of depression ${ }^{b}$} \\
\hline No & 1,287 & 89.0 \\
\hline Yes & 155 & 11.0 \\
\hline \multicolumn{3}{|l|}{ Use of alcohol } \\
\hline Never & 169 & 11.1 \\
\hline At least once & 1,350 & 88.9 \\
\hline \multicolumn{3}{|c|}{ Age of first experience with alcohol (years) } \\
\hline$<18$ & 853 & 64.9 \\
\hline$\geq 18$ & 458 & 35.1 \\
\hline
\end{tabular}

ABEP: Associação Brasileira de Empresas de Pesquisa (Brazilian Association of Research Companies)

${ }^{\text {a }}$ Different sample values because of missing data.

${ }^{\mathrm{b}}$ Edinburgh postnatal depression scale - cutoff point $\geq 13$.

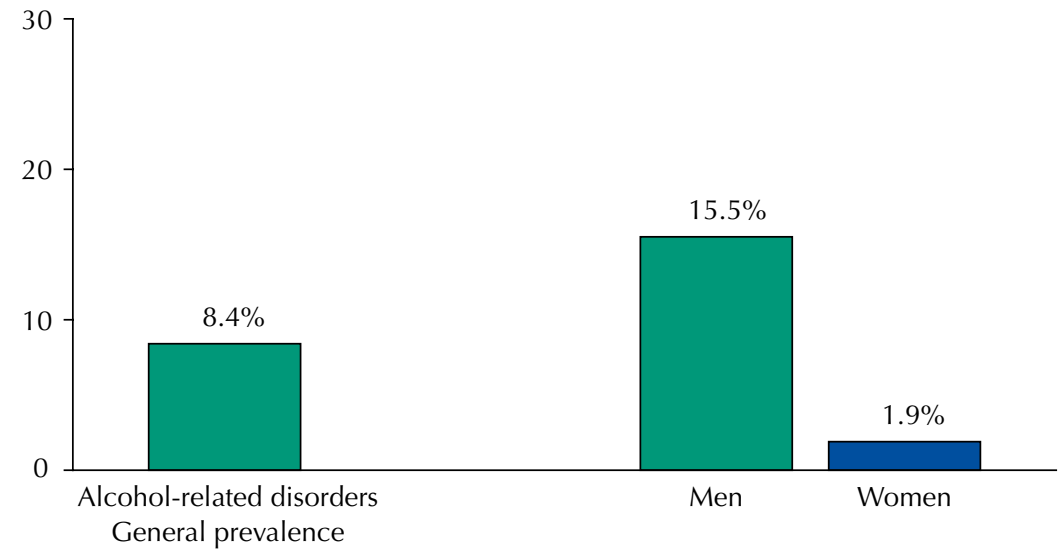

Figure 1. Prevalence of alcohol-related disorders (AUDIT $\geq 8$ ) in adults living in the rural area of Pelotas, State of Rio Grande do Sul, Brazil, 2016.

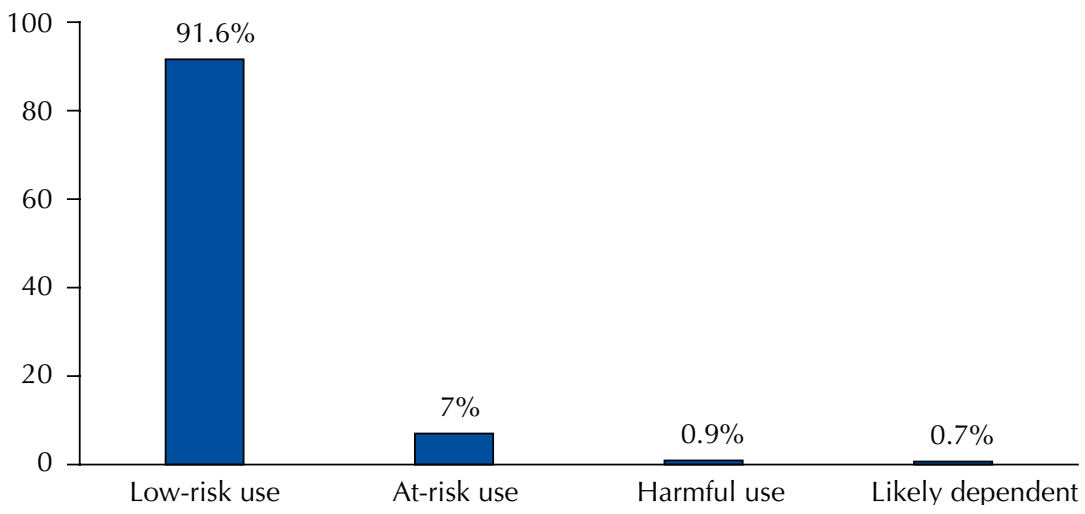

Figure 2. Categories of pattern of alcohol consumption in adults living in the rural area of Pelotas, State of Rio Grande do Sul, Brazil, 2016. 
Table 2. Multivariate analysis of alcohol-related disorders (AUDIT $\geq 8$ ) and exposure variables. Persons aged 18 years or over living in the rural area of the city of Pelotas, State of Rio Grande do Sul, Brazil, 2016.

\begin{tabular}{|c|c|c|c|c|}
\hline \multirow{2}{*}{ Variable } & \multicolumn{2}{|c|}{ Unadjusted analysis } & \multicolumn{2}{|c|}{ Adjusted analysis } \\
\hline & n (\%) & PR $(95 \% \mathrm{Cl})$ & n (\%) & PR $(95 \% \mathrm{Cl})$ \\
\hline \multicolumn{5}{|c|}{ 1st level ${ }^{c}$} \\
\hline Sex & & $\mathrm{p}<0.001^{\mathrm{a}}$ & & $\mathrm{p}<0.001^{\mathrm{a}}$ \\
\hline Male & $112(15.3)$ & $8.27(4.80-14.24)$ & $111(15.2)$ & $8.26(4.82-14.16)$ \\
\hline Female & $15(1.9)$ & 1 & $15(1.9)$ & 1 \\
\hline Age groups (years) ${ }^{\mathrm{a}}$ & & $\mathrm{p}<0.001^{\mathrm{b}}$ & & $p=0.001^{b}$ \\
\hline $18-29$ & 34 (11.9) & $3.57(1.94-6.56)$ & 34 (11.9) & $3.29(1.8-6.0)$ \\
\hline $30-39$ & $24(10.5)$ & $3.24(1.60-6.55)$ & $24(10.5)$ & $2.94(1.42-6.13)$ \\
\hline $40-49$ & $27(9.2)$ & $2.80(1.57-4.89)$ & $27(9.2)$ & $2.56(1.39-4.68)$ \\
\hline $50-59$ & $29(9.7)$ & $3.04(1.61-5.71)$ & $28(9.4)$ & $2.86(1.53-5.34)$ \\
\hline$\geq 60$ & $13(3.2)$ & 1 & $13(3.2)$ & 1 \\
\hline Race & & $p=0.224^{a}$ & & $p=0.145^{a}$ \\
\hline Other & $2(6.7)$ & $0.96(0.23-3.98)$ & $2(6.7)$ & $0.76(0.19-2.94)$ \\
\hline Black/Brown & $22(11.4)$ & $1.46(0.94-2.25)$ & $22(11.5)$ & $1.43(1.00-2.05)$ \\
\hline White & $103(8.0)$ & 1 & $102(7.9)$ & 1 \\
\hline Family history & & $p=0.184^{a}$ & & $p=0.067^{a}$ \\
\hline No & $82(7.6)$ & $0.76(0.51-1.14)$ & $82(7.6)$ & $0.72(0.51-1.02)$ \\
\hline Yes & $44(10.0)$ & 1 & $44(10.0)$ & 1 \\
\hline \multicolumn{5}{|c|}{ 2nd level ${ }^{\mathrm{d}}$} \\
\hline Education level (full years) & & $p=0.108^{a}$ & & $\mathrm{p}=0.013^{\mathrm{a}}$ \\
\hline $0-4$ & $30(6.3)$ & $0.41(0.15-1.10)$ & $30(6.3)$ & $0.42(0.18-1.01)$ \\
\hline $5-8$ & $64(9.9)$ & $0.64(0.26-1.57)$ & $64(9.9)$ & $0.57(0.26-1.24)$ \\
\hline $9-11$ & $27(7.5)$ & $0.46(0.21-1.00)$ & $27(7.5)$ & $0.33(0.16-0.69)$ \\
\hline$\geq 12$ & $6(16.2)$ & 1 & $6(16.2)$ & 1 \\
\hline Marital status & & $p=0.018^{a}$ & & $p=0.273^{a}$ \\
\hline Single & 55 (13.9) & $2.02(1.24-3.29)$ & $55(13.9)$ & $1.41(0.82-2.44)$ \\
\hline Divorced/Widower/Separated & $10(4.9)$ & $0.73(0.40-1.30)$ & $10(5.0)$ & $1.32(0.70-2.52)$ \\
\hline Current work & & $\mathrm{p}<0.001^{\mathrm{a}}$ & & $p=0.114^{a}$ \\
\hline No & $29(4.7)$ & $0.41(0.28-0.60)$ & $29(4.7)$ & $0.69(0.44-1.10)$ \\
\hline Yes & $98(11.0)$ & 1 & $98(11.0)$ & 1 \\
\hline ABEP & & $p=0.190^{a}$ & & $\mathrm{p}=0.192^{\mathrm{a}}$ \\
\hline$A$ or $B$ & $30(9.6)$ & $0.89(0.49-1.60)$ & $30(9.6)$ & $0.88(0.50-1.53)$ \\
\hline $\mathrm{C}$ & $58(6.8)$ & $0.64(0.40-1.04)$ & $58(6.8)$ & $0.66(0.42-1.03)$ \\
\hline $\mathrm{D}$ or $\mathrm{E}$ & $35(10.4)$ & 1 & $34(10.1)$ & 1 \\
\hline Religious choice & & $p=0.008^{a}$ & & $p=0.09^{a}$ \\
\hline Evangelical & $33(5.6)$ & $0.46(0.27-0.78)$ & $33(5.6)$ & $0.70(0.38-1.30)$ \\
\hline Other & $8(7.3)$ & $0.60(0.27-1.32)$ & $8(7.3)$ & $0.92(0.45-1.85)$ \\
\hline Catholic & $61(10.2)$ & $0.85(0.54-1.32)$ & $61(10.2)$ & $1.25(0.79-1.98)$ \\
\hline No religion & $25(11.8)$ & 1 & $24(11.4)$ & 1 \\
\hline \multicolumn{5}{|c|}{3 rd levele } \\
\hline Religious practice & & $\mathrm{p}<0.001^{\mathrm{a}}$ & & $p=0.02^{a}$ \\
\hline Zero/month & $73(11.4)$ & $2.55(1.72-3.78)$ & $73(11.4)$ & $1.62(1.08-2.43)$ \\
\hline$\geq 1 /$ month & $29(4.4)$ & 1 & $29(4.4)$ & 1 \\
\hline \multicolumn{5}{|c|}{ 4th levelf } \\
\hline Smoking & & $\mathrm{p}<0.001^{b}$ & & $p=0.033^{b}$ \\
\hline Smoker & $43(17.4)$ & $3.00(1.87-4.81)$ & $31(17.4)$ & $1.88(1.03-3.43)$ \\
\hline Former smoker & $28(9.8)$ & $1.69(1.16-2.46)$ & $25(11.4)$ & $1.29(0.81-2.05)$ \\
\hline Never smoked & $56(5.7)$ & 1 & $44(6.4)$ & 1 \\
\hline Diagnosis of depression & & $p=0.396^{a}$ & & $\mathrm{p}=0.814^{\mathrm{a}}$ \\
\hline No & $11(7.0)$ & $0.75(0.39-1.46)$ & $6(5.8)$ & $0.90(0.39-2.10)$ \\
\hline Yes & $114(8.8)$ & 1 & $94(9.6)$ & 1 \\
\hline Age of first experience with alcohol (years) & & $\mathrm{p}=0.012^{\mathrm{a}}$ & & $p=0.189^{a}$ \\
\hline$<18$ & $97(11.4)$ & $1.66(1.12-2.46)$ & $75(10.7)$ & $1.31(0.86-2.00)$ \\
\hline$\geq 18$ & $30(6.5)$ & 1 & $25(6.5)$ & 1 \\
\hline
\end{tabular}

ABEP: Associação Brasileira de Empresas de Pesquisa (Brazilian Association of Research Companies)

a P-value of the test of heterogeneity.

${ }^{\mathrm{b}} \mathrm{P}$-value of the linear trend.

c Adjustment for all variables of the first level.

${ }^{d}$ Adjustment for the variables of the 1 st level with $\mathrm{p}<0.20$ and for all variables of the 2 nd level.

${ }^{\mathrm{e}}$ Adjustment for upper level variables with $\mathrm{p}<0.20$ and for religious practice.

${ }^{f}$ Adjustment for upper level variables with $p<0.20$ and for variables of the level. 
In the multivariable analysis, the risk of alcohol-related disorders, the AUDIT category of outcome used, was higher in males ( $\mathrm{PR}=8.26,95 \% \mathrm{CI} 4.82-14.16)$. The age group of $18-29$ years presented a prevalence 3.3 times higher (95\%CI 1.80-6.00) than the category of 60 years or over. In addition, the other categories also presented higher prevalences in relation to the reference group, but they tended to decrease with increasing age $(\mathrm{p}<0.001)$ (Table 2).

In the category of education level, those who completed nine to 11 years of school presented a lower prevalence of the outcome than the reference category, i.e., those with 12 years or more of study ( $\mathrm{PR}=0.33,95 \% \mathrm{CI} 0.16-0.69$ ). The other categories also presented lower prevalences, but without statistical significance.

Individuals who self-reported as Evangelicals had a lower prevalence of outcome than those without religion ( $\mathrm{PR}=0.70,95 \% \mathrm{CI} 0.38-1.30$ ), but the association was not statistically significant. Religious practice one or more times in the last 30 days was also a protective factor for the presence of alcohol-related disorders. Those who had no religious practice in the last 30 days had a 1.6 times higher prevalence (95\%CI 1.08-2.43) (Table 2).

We also found a relation between smoking and alcohol-related disorders. After the adjusted analysis, current smokers had a 1.9 times higher prevalence of alcohol-related disorders (95\%CI 1.03-3.43) than those who had never smoked (Table 2).

\section{DISCUSSION}

The prevalence of alcohol-related disorders (AUDIT $\geq 8$ ) found in this study was $8.4 \%$. We found higher prevalences among males, the 18-29 age group, those who did not practice their religion, and smokers.

We found no association between the outcome variable, i.e., alcohol-related disorders, and the following exposure variables: marital status, family history of alcohol problems, social class, religious choice, likely diagnosis of depression, and age of first experience with alcohol.

Overall, the prevalence of $8.4 \%$ of alcohol-related disorders was lower than those found in many studies on the subject ${ }^{8,11,12,21-23}$. For example, in rural regions in India, the prevalence of at-risk alcohol consumption (AUDIT $\geq 8$ ) was $33.2 \%{ }^{24}$.

Prevalence findings, however, are similar to those found in other studies. The PNS, for example, has found a prevalence of alcohol abuse of $10.3 \%$ in adult individuals living in rural areas of Brazil ${ }^{3}$. In predominantly rural quilombola communities in Bahia, the prevalence of excessive alcohol consumption was $10.7 \%^{10}$. In 2013, in India, a study using the same instrument and the same cutoff point as we used found a prevalence of $9.4 \%^{11}$. Another study carried out in a rural region of Kenya has found a prevalence of $7.7 \%$ of alcohol-related disorders, using the AUDIT questionnaire and cutoff point $\geq 8^{25}$.

To compare the different prevalences found in some studies, it is important to take into account the measurement methods used, such as the questionnaire and cutoff point, for example. Two studies conducted in Brazil, in the cities of Florianópolis, State of Santa Catarina, and Rio Grande, State of Rio Grande do Sul, have used the AUDIT questionnaire with the same cutoff point as this study ${ }^{7,21}$, which allows us to better compare the findings. The prevalence found in this study is very close to that found in Rio Grande, of $7.9 \%$, a city close to Pelotas and with very similar characteristics, and it is different from the prevalence of 18.4\% found in Florianópolis. This result may indicate that the characteristics of different regions and populations studied, such as the number of inhabitants and cultural habits, may be related to different patterns of consumption.

Particularly in Brazil, there are few studies conducted exclusively with rural populations, which limits comparability with the results found. With the data currently available, we can see that the prevalence found in this study in the rural area of Pelotas was lower 
than that identified in the urban area of this city ${ }^{8}$, which may be due to differences in the methods used in both studies. Two other large studies evaluating all regions of the country have also found lower prevalences of at-risk consumption in rural areas. These results may suggest that at-risk alcohol consumption is lower in rural populations than in urban populations ${ }^{2,3,8}$.

The factor most strongly associated with alcohol-related disorders in this study was being male, which corroborates almost all studies on the subject ${ }^{8,9,21}$. The literature has shown that men drink more than women, which may partially explain the higher prevalence of at-risk consumption in this group ${ }^{2,3}$. Although there is no solid explanation for this association, the complex combination of genetic, behavioral, and cultural factors for men may play an important role ${ }^{26}$.

Regarding age group, the main risk factor belonged to the group between 18-29 years, as shown by most studies ${ }^{9,23}$. Some factors could act as a risk for younger persons, such as the transitional phase of life (entry into adult life), higher frequency of personal and family conflicts, and greater susceptibility to advertising campaigns that encourage alcohol consumption ${ }^{23,27}$. It is important to point out, for a better interpretation of this result, that the method used in this study, the score in AUDIT $\geq 8$, allows us to detect from lighter patterns of consumption to more severe patterns. Higher prevalences in younger age groups may be due to the higher number of individuals with milder patterns of at-risk consumption, but which are already considered, by the classification adopted, as alcoholrelated disorders.

This study did not find a statistically significant association between marital status and alcohol-related disorders. However, single individuals had higher prevalences than those married or living with a partner ${ }^{7,28}$. One possible explanation for this relationship may be that individuals in more stable relationships have better health-related habits ${ }^{29}$. The size of the sample studied may not have been enough to find a statistically significant association.

Regarding religious choice, although the association was not statistically significant, we found results that are similar to other studies on the subject. Individuals who claim to be Evangelical had lower prevalences of alcohol-related disorders ${ }^{23}$. In addition, individuals who practice their religions, that is, attend one or more times a month places of practice, presented lower prevalences of the outcome studied. This association is likely to be related to a broader context of support and social support. We can also understand this association by thinking about the guidance of each religion (some with a greater emphasis on healthy behaviors and habits, such as abstinence from alcohol) and how adepts follow it ${ }^{23}$.

This study also found a positive association between smoking and alcohol-related disorders. Smokers presented higher prevalences than former smokers and those who never smoked, as already found in the current literature ${ }^{8,11,21}$. The explanation for this double addiction may lie in the complex genetic-environmental interaction, possibly from a common cause of the two behaviors, be it genetic characteristics predisposing to addiction, environmental exposure to chemicals consumed by relatives, or both conditions ${ }^{30}$.

The great differential of this research is that it is a population-based study with an exclusively rural population. However, some limitations are relevant and need to be highlighted and discussed. Our sampling process may have reduced the participation of very distant households in the research ${ }^{16}$. However, even though it is a limitation, we believe that it has not been able to distort the results found. Another condition that should be thought of as a limitation is the way how alcohol consumption was researched. The questionnaire was applied with interviews and not self-administered questionnaires, which may have led some individuals to minimize their pattern of consumption. This limitation may have led to an underestimation of the prevalence of alcohol-related disorders. However, we believe that the truly underestimated value was the most severe patterns of consumption, with AUDIT score $\geq 20$. 
Other possible limitations come from the study having a cross-sectional design. Causal inferences are limited, which demands a careful interpretation of the data. In addition, there is the possibility of reverse causality in some associations, such as marital status, smoking, and religious choice and practice. We believe that association with religious practice should be better understood in future studies, with designs more suitable for it. It is possible that current abstainers have sought religion as a way to help them with their alcohol-related problems.

The generalization of the results of this research is probably limited, since we studied a specific rural population. Rural regions of different places in Brazil may have peculiar characteristics in relation to different habits, such as the consumption of alcohol. However, we believe that this study is an improvement in the knowledge on less studied populations, such as rural ones, and it is a possible motivator for further research with populations living in rural areas of other regions in Brazil.

The prevalence of alcohol-related disorders in the rural population studied is high, but it is lower than those found by other studies in the country, mostly in urban populations. The factors associated with alcohol-related disorders found are similar to those identified in other studies. This knowledge from repeated findings contributes to the adoption of public health measures at different levels of prevention. However, there is a clear lack of data on alcohol consumption in rural populations in Brazil. More studies need to be carried out with rural populations in order to further the knowledge on their characteristics and needs.

\section{REFERENCES}

1. Laranjeira R, Pinsky I, Sanches M, Zaleski M, Caetano R. Alcohol use patterns among Brazilian adults. Rev Bras Psiquiatr. 2010;32(3):231-41. https://doi.org/10.1590/S1516-44462009005000012

2. Laranjeira R, diretor, Madruga CS, coordenadora; Equipe UNIAD. II LENAD Levantamento Nacional de Álcool e Drogas 2012. São Paulo: Instituto Nacional de Ciência e Tecnologia para Políticas Públicas de Álcool e Outras Drogas (INPAD) UNIFESP; 2014 [cited 2018 Feb 13]. Available from: http://inpad.org.br/wp-content/ uploads/2014/03/Lenad-II-Relatório.pdf

3. Instituto Brasileiro de Geografia e Estatística. Pesquisa Nacional de Saúde (PNS) 2013: percepção do estado de saúde, estilos de vida e doenças crônicas: Brasil, Grandes Regiões e Unidades da Federação. Rio de Janeiro: IBGE; MS; 2014 [cited 2018 Feb 13]. Available from: ftp://ftp.ibge.gov.br/PNS/2013/pns2013.pdf

4. World Health Organization. Global status report on alcohol and health 2014. Geneva: WHO; 2014 [cited 2018 Feb 13]. Available from: http://apps.who.int/iris/ bitstream/10665/112736/1/9789240692763_eng.pdf

5. Babor TF, Higgins-Biddle JC, Saunders JB, Monteiro MG. AUDIT - The Alcohol Use Disorders Identification Test: guidelines for use in Primary Care. 2.ed. Geneva: WHO; 2001 [cited 2018 Feb 13]. Available from: whqlibdoc.who.int/hq/2001/WHO_MSD_MSB_01.6a.pdf

6. Rehm J, Mathers C, Popova S, Thavorncharoensap M, Teerawattananon Y, Patra J. Global burden of disease and injury and economic cost attributable to alcohol use and alcohol-use disorders. Lancet. 2009;373(9682):2223-33. https://doi.org/10.1016/S0140-6736(09)60746-7

7. Reisdorfer E, Büchele F, Pires ROM, Boing AF. Prevalence and associated factors with alcohol use disorders among adults: a population-based study in southern Brazil. Rev Bras Epidemiol. 2012;15(3):582-94. https://doi.org/10.1590/S1415-790X2012000300012

8. Costa JSD, Silveira MF, Gazalle FK, Oliveira SS, Hallal PC, Menezes AMB, et al. Heavy alcohol consumption and associated factors: a population-based study. Rev Saude Publica. 2004;38(2):284-91. https://doi.org/10.1590/S0034-89102004000200019

9. Garcia LP, Freitas LRS. Consumo abusivo de álcool no Brasil: resultados da Pesquisa Nacional de Saúde 2013. Epidemiol Serv Saude. 2015;24(2):227-37. https://doi.org/10.5123/S1679- 49742015000200005 
10. Cardoso LGV, Melo APS, Cesar CC. Prevalência do consumo moderado e excessivo de álcool e fatores associados entre residentes de Comunidades Quilombolas de Vitória da Conquista, Bahia, Brasil. Cienc Saude Coletiva. 2015;20(3):809-20. https://doi.org/10.1590/1413- 81232015203.12702014

11. Kumar SG, Premarajan KC, Subitha L, Suguna E, Vinayagamoorthy, Kumar V. Prevalence and pattern of alcohol consumption using Alcohol Use Disorders Identification Test (AUDIT) in rural Tamil Nadu, India. J Clin Diagn Res. 2013;7(8):1637-9. https://doi.org/10.7860/JCDR/2013/5521.3216

12. Giang KB, Van Minh H, Allebeck P. Alcohol consumption and household expenditure on alcohol in a rural district in Vietnam. Glob Health Action. 2013;6:18937. https://doi.org/10.3402/gha.v6i0.18937

13. Barros AJD, Menezes AMB, Santos IS, Assunção MCF, Gigante D, Fassa AG, et al. O Mestrado do Programa de Pós-graduação em Epidemiologia da UFPel baseado em consórcio de pesquisa: uma experiência inovadora. Rev Bras Epidemiol. 2008;11 Supl 1:133-44. https://doi.org/10.1590/S1415-790X2008000500014

14. Instituto Brasileiro de Geografia e Estatística. XII Censo Demográfico Brasil 2010: Cidades. Rio de Janeiro: WHO; 2001 [cited 2018 Feb 13]. Available from: https://cidades.ibge.gov.br/brasil/rs/ pelotas/panorama

15. Sullivan KM, Dean A, Soe MM. OpenEpi: a Web-based epidemiologic and statistical calculator for Public Health. Public Health Rep. 009;124(3):471-4. https://doi.org/10.1177/003335490912400320

16. Gonçalves H, Tomasi E, Tovo-Rodrigues L, Bielemann RM, Machado AKF, Ruivo ACO, et al. Estudo de base populacional na zona rural: metodologia e desafios. Rev Saude Publica. 2018;52 Supl 1:3s. https://doi.org/10.11606/S1518-8787.2018052000270

17. Méndez BE. Uma versão brasileira do AUDIT (Alcohol Use Disorders Identification Test) [dissertation]. Pelotas: Universidade Federal de Pelotas; 1999.

18. Associação Brasileira de Empresas de Pesquisa. Critério de Classificação Econômica do Brasil. São Paulo: ABEP; 2014 [cited 2018 Feb 13]. Available from: http://www.abep.org

19. Matijasevich A, Munhoz TN, Tavares BF, Barbosa APPN, Silva DM, Abitante MS, et al. Validation of the Edinburgh Postnatal Depression Scale (EPDS) for screening of major depressive episode among adults from the general population. BMC Psychiatry. 2014;14:284. https://doi.org/10.1186/s12888-014-0284-x

20. Victora CG, Huttly SR, Fuchs SC, Olinto MT. The role of conceptual frameworks in epidemiological analysis: a hierarchical approach. Int J Epidemiol. 1997;26(1):224-7. https://doi.org/10.1093/ije/26.1.224

21. Mendoza-Sassi RA, Beria JU. Prevalence of alcohol use disorders and associated factors: a population-based study using AUDIT in southern Brazil. Addiction. 2003;98(6):799-804. https://doi.org/10.1046/j.1360-0443.2003.00411.x

22. Primo NLNP, Stein AT. Prevalência do abuso e da dependência de álcool em Rio Grande (RS): um estudo transversal de base populacional. Rev Psiquiatr Rio Gd Sul. 2004;26(3):280-6. https://doi.org/10.1590/S0101-81082004000300005

23. Ferreira LN, Bispo Júnior JP, Sales ZN, Casotti CA, Braga Junior ACR. Prevalência e fatores associados ao consumo abusivo e à dependência de álcool. Cienc Saude Coletiva. 2013;18(11):3409-18. https://doi.org/10.1590/S1413- 81232013001100030

24. Rathod SD, Nadkarni A, Bhana A, Shidhaye R. Epidemiological features of alcohol use in rural India: a population-based cross-sectional study. BMJ Open. 2015;5(12):e009802. https://doi.org/10.1136/bmjopen-2015-009802

25. Takahashi R, Wilunda C, Magutah K, Mwaura-Tenambergen W, Wilunda B, Perngparn U. Correlates of alcohol consumption in rural western Kenya: a cross-sectional study. BMC Psychiatry. 2017;17(1):175. https://doi.org/10.1186/s12888-017-1344-9

26. Merikangas KR, Stolar M, Stevens DE, Goulet J, Preisig MA, Fenton B, et al. Familial transmission of substance use disorders. Arch Gen Psychiatry. 1998;55(11):973-9. https://doi.org/10.1001/archpsyc.55.11.973

27. Pinsky I, El Jundi SARJ. O impacto da publicidade de bebidas alcoólicas sobre o consumo entre jovens: revisão da literatura internacional. Rev Bras Psiquiatr. 2008;30(4):362-74. https://doi.org/10.1590/S1516-44462008005000015 
28. Freitas ICM, Moraes SA. Dependência de álcool e fatores associados em adultos residentes em Ribeirão Preto, São Paulo, Brasil, 2006: Projeto OBEDIARP. Cad Saude Publica. 2011;27(10):2021-31. https://doi.org/10.1590/S0102-311X2011001000015

29. Derrick JL, Leonard KE, Quigley BM, Houston RJ, Testa M, Kubiak A. Relationship-specific alcohol expectancies in couples with concordant and discrepant drinking patterns. J Stud Alcohol Drugs. 2010;71(5):761-8. https://doi.org/10.15288/jsad.2010.71.761

30. Skalamera J, Hummer RA. Educational attainment and the clustering of health-related behavior among U.S. young adults. Prev Med. 2016;84:83-9. https://doi.org/10.1016/j.ypmed.2015.12.011

Funding: Programa de Excelência Acadêmica da Coordenação de Aperfeiçoamento de Pessoal de Nível Superior (PROEX/CAPES - Process 23038.002445/2015-97, benefit number 1012/2015).

Authors' Contribution: Design and planning of the study: GPJ, MFS. Collection, analysis, and interpretation of the data: GPJ, CLM, MFS. Preparation or review of the study: GPJ, CLM, MFS. All authors have approved the final version of the study and assume public responsibility for its content.

Conflict of Interest: The authors declare no conflict of interest. 